\section{PKS}

PUBLIC

KNOWLEDGE

PROJECT

\section{REVISTA ENSINO DE GEOGRAFIA OJS (RECIFE)

\title{
GEOGRAFIA ESCOLAR E AVALAIAÇÃO DA APRENDIZAGEM: UMA REFLEXÃO A PARTIR DAS AULAS DE GEOGRAFIA EM UMA ESCOLA PÚBLICA DE SÃO JOÃO DO SABUGI-RN
}

\author{
Elaine Cristina de Medeiros Pereira \\ Universidade Federal do Rio Grande do Norte (UFRN) \\ Djanni Martinho dos Santos Sobrinho \\ Universidade Federal do Rio Grande do Norte (UFRN) \\ Tânia Cristina Meira Garcia \\ Universidade Federal do Rio Grande do Norte (UFRN)
}

\begin{abstract}
RESUMO: O trabalho pedagógico da Geografia Escolar necessita está bem organizado, pautado em planejamentos que visem a selecionar conteúdos de ensino, propor metodologias e realizar a avaliação da aprendizagem por meio de instrumentos avaliativos que influenciem significativamente no interesse em aprender do educando e proporcione mecanismos que ajudem esse sujeito a assumir posições diante das mais diversas situações sociais. Assim, esse trabalho busca compreender as práticas avaliativas dos professores nas aulas de Geografia dos Anos Iniciais do Ensino Fundamental, na Escola Estadual Senador José Bernardo, localizada na cidade de São João do Sabugi - RN. Em se tratando de percurso metodológico, foram realizadas pesquisas bibliográficas a autores como: Libâneo (1994), Luckesi (2011), Rabelo e Bueno (2015), Stefanello (2009), Turra (1986), Villas Boas (2004), entre outros, além de pesquisa documental e de campo, através de visitas a instituição e observações das aulas de Geografia. A partir dos dados coletados, constatou-se que o mais importante durante o processo avaliativo do aluno é que o docente seja capaz de identificar as dificuldades existentes e, através disso, buscar soluções para suprir as necessidades, com o intuito de permitir que o sujeito aprenda e desenvolva seus aspectos cognitivos.
\end{abstract}

Palavras-Chave: Geografia Escolar. Avaliação da Aprendizagem. Anos Iniciais do Ensino Fundamental. 
SCHOOL GEOGRAPHY AND EVALUATION OF LEARNING: A REFLECTION FROM GEOGRAPHY LESSONS IN A PUBLIC SCHOOL OF SÃO JOÃO DO SABUGI-RN

ABSTRACT: The pedagogical work of School Geography needs to be well organized, based on planning to select teaching contents, propose methodologies and carry out the evaluation of learning through evaluation instruments that significantly influence the student's interest in learning and provide mechanisms that help this subject to take positions in the most diverse social situations. Thus, this work seeks to understand the evaluative practices of teachers in the Geography classes of the Early Years of Elementary School, in the Senador José Bernardo State School, located in the city of São João do Sabugi - RN. As a methodological approach, bibliographical research was carried out for authors such as: Libano (1994), Luckesi (2011), Rabelo and Bueno (2015), Stefanello (2009), Turra (1986), Villas Boas (2004), among others , in addition to documentary and field research, through visits to the institution and observations of the Geography classes. From the collected data, it was verified that the most important during the evaluation process of the student is that the teacher is able to identify the existing difficulties and, through this, to find solutions to meet the needs, with the intention of allowing the subject learn and develop your cognitive aspects.

Keywords: School Geography. Learning Assessment. Early Years of Elementary Education.

\section{INDRODUÇÃO}

O trabalho pedagógico da Geografia Escolar necessita está bem organizado, pautado em planejamentos que visem a selecionar conteúdos de ensino, propor metodologias e realizar a avaliação da aprendizagem por meio de instrumentos avaliativos. Esses aspectos devem ser organizados e utilizados de forma que influenciem significativamente no interesse em aprender do educando e proporcione mecanismos que ajudem esse sujeito a assumir posições diante das mais diversas situações sociais.

O educando não busca a escola apenas para captar informações, assimilar conteúdos e ser submetido a um processo de seleção, mas sim, para aprender e construir conhecimentos ao longo da sua vida escolar. Dessa maneira, a avaliação estará de prontidão a serviço dessa tarefa e caberá ao professor desenvolvê-la da melhor forma, a fim de refletir sobre suas práticas e metodologias de ensino e, ao mesmo tempo, identificar o desempenho individual e coletivo dos estudantes.

Dessa forma, essa produção busca compreender as práticas avaliativas dos professores nas aulas de Geografia dos Anos Iniciais do Ensino Fundamental, na Escola Estadual Senador José Bernardo, localizada na cidade de São João do Sabugi - RN, identificando qual o tipo de avaliação é predominante nesse componente curricular e os instrumentos avaliativos mais usados durante as observações. 
Em se tratando de percurso metodológico, foram realizadas pesquisas bibliográficas a autores como: Libâneo (1994), Luckesi (2011), Rabelo e Bueno (2015), Stefanello (2009), Turra (1986), Villas Boas (2004), entre outros, além de pesquisa documental e de campo, através de visitas a instituição para a realização de observações das aulas de Geografia nos Anos Iniciais do Ensino Fundamental.

Com análise e descrição dos dados coletados, este trabalho contribuirá de forma significativa para o processo de formação profissional e pessoal do pesquisador, visto que a oportunidade trará novas informações científicas sobre o assunto e a realidade estudada, além de falar da base para pesquisas futuras e para a escola.

\section{A LOCALIZAÇÃo E O CONTEXTO HISTÓRICO DA INSTITUIÇÃO EDUCACIONAL}

A Escola Estadual Senador José Bernardo - EESJB, está situada na Avenida Honório Maciel, 354, no centro da cidade de São João do Sabugi/RN. Devido a sua localização, a instituição favorece o acesso do aluno, pois encontra-se na rua principal da cidade, o que permite ser localizada com facilidade até mesmo por quem não é morador da localidade.

Trata-se de uma instituição pertinente à rede pública estadual de ensino, com jurisdição da $10^{\mathrm{a}}$ DIRED, Diretoria Regional de Educação, com sede em Caicó-RN, a qual possui como órgão maior de gestão administrativa a Secretaria de Estado da Educação e da Cultura do estado do Rio Grande do Norte (SEEC/RN).

De acordo com as informações contidas no Projeto Político Pedagógico (PPP), a escola teve sua fundação no ano de 1924 e por isso é considerada como a mais antiga, em funcionamento, do município de São João do Sabugi-RN. Um fato importante sobre sua história é a construção de sua estrutura física própria que se deu a partir de uma campanha liderada por um morador da cidade, Francisco Quinino de Medeiros, que arrecadou tijolos, algodão, além de outros produtos e materiais que foram usados ou vendidos para adquirir os recursos necessários para sua edificação.

Em relação às questões legais de funcionamento, a referida instituição é mantida pelo Poder Público e administrada pela SEEC, conforme os seguintes atos administrativos:

- Autorização: Portaria n 0 $^{4} 2$ 2/80 - SEC/GS de 20/05/1980, publicada em DOE de 22/08/1980, autoriza o funcionamento do Ensino de $1^{\circ}$ grau, retroagindo ao ano de 1924. 
- Transformação: Decreto no 8863, de 01/02/1984 publicado no DOE No 5748 em 02/02/1984 retroagindo seus efeitos a 01/01//1983, transforma a Escola Estadual Senador José Bernardo em estabelecimento de ensino de $1^{\circ}$ e $2^{\circ}$ graus.

- Transformação: Decreto no 12.509 de 13/02/1995 - DOE edição de 14/02/1995, transforma Escolas Estaduais em Centros Escolares e dá outras providências;

- Decreto $\mathrm{n}^{\mathrm{o}} 12.670$ de 14/07/1995, DOE edição de 17/07/1995, modifica os anexos I, II e III constantes nos artigos $1^{\circ}, 6^{\circ}$ e $7^{\circ}$ do Decreto $n^{\circ} 12.509$;

- Decreto $n^{\circ} 14.379$ de 24/03/1999, DOE 25/03/1999 transforma os Centros Escolares em Escolas. Centro Escolar Senador José Bernardo para Escola Estadual Senador José Bernardo ${ }^{1}$.

Os decretos anteriormente citados correspondem ao percurso legal que a instituição vivenciou nos últimos tempos. De tal modo, essas modificações declaradas a partir de documentos demonstram o avanço significativo que a instituição teve em relação aos acontecimentos da época, voltados principalmente para a educação no cenário brasileiro. Dentre esses aspectos, pode-se ressaltar a importância de se ter, na própria cidade, uma escola que ofertasse o ensino de segundo grau, atual ensino médio. Assim, a população sabugiense não necessitaria buscar essa etapa de ensino em outro município.

\subsection{O PERFIL DOS DOCENTES}

A escola baseia-se nas concepções e finalidades elencadas para escola pública brasileira, definidas por meio da Constituição Federal e pela Lei de Diretrizes e Bases da Educação Nacional (LDB $\mathrm{n}^{\circ}$ 9.394/96). De acordo com o PPP, a instituição busca desempenhar um trabalho pedagógico, que visa o pleno desenvolvimento do estudante, na preparação para o exercício da cidadania e nas competências para o mundo do trabalho.

Para isso, busca possibilitar condições semelhantes para que todos os alunos ampliem suas capacidades e compreendam os aspectos necessários para a vida em sociedade, de forma que possam identificar a realidade existente e, assim, ter uma postura responsável e consciente para a promoção da melhoria na qualidade de vida.

Para conseguir desempenhar o seu trabalho, a escola conta com o apoio de um corpo docente formado por vinte e dois professores, sendo vinte e um efetivos e um contratado pelo processo seletivo de 2017. Esses profissionais possuem idades que variam dos 29 aos 46 anos, com entrada no serviço púbico que vão do ano de 1988 até 2017. Do total de professores aqui descrito, quatorze dispõem de dois vínculos empregatícios e os demais, apenas um. Isso implica dizer que uma parcela significativa do corpo docente é composta por profissionais que atuam em mais de um estabelecimento de ensino, o que não é uma tarefa fácil, pois, para isso,

\footnotetext{
${ }^{1}$ Informações retiradas do Projeto Político Pedagógico da Escola Estadual Senador José Bernardo.
} 
são necessários dedicação, empenho e responsabilidade em dobro por parte dessas pessoas, o que pode implicar em uma rotina exaustiva.

A equipe é distribuída nos Anos Iniciais e Finais do Ensino Fundamental, no Ensino Médio e na modalidade da Educação de Jovens e Adultos. Os horários de atuação são organizados pela gestão, que busca sempre respeitar as especificidades e carga horária de cada um.

Todos os professores possuem graduação em licenciatura plena na área que atuam e apenas três ainda não deram continuidade com uma especialização ou pós-graduação, mas, em conversa, deixaram evidente o interesse futuro a isso. Os demais docentes dispõem de formação em nível de especialização, com a presença de uma professora com doutorado completo, uma com mestrado completo e cinco cursando o mestrado.

A qualificação profissional desses educadores contribui para um melhor desempenho da instituição, visto que as aulas são organizadas e mediadas por pessoas capacitadas e com intuito de contribuir no processo de formação pessoal e intelectual do educando.

Sobre a formação desses profissionais, é indispensável destacar o que aponta a Lei de Diretrizes e Bases da Educação (LDB) - 9.394/96:

\footnotetext{
Art. 61. A formação de profissionais da educação, de modo a atender aos objetivos dos diferentes níveis e modalidades de ensino e as características de cada fase do desenvolvimento do educando, terá como fundamentos:

I - a associação entre teorias e práticas, inclusive mediante a capacitação em serviço;

II - aproveitamento da formação e experiências anteriores em instituições de ensino e outras atividades.

Art. 62. A formação de docentes para atuar na educação básica far-se-á em nível superior, em curso de licenciatura, de graduação plena, em universidades e institutos superiores de educação, admitida, como formação mínima para o exercício do magistério na educação infantil e nas quatro primeiras séries do ensino fundamental, a oferecida em nível médio na modalidade Normal. (BRASIL, 1996, p. 20).
}

Dessa maneira, o desempenho do professor na área de formação e a busca por ampliação dos conhecimentos através das formações continuadas por eles desempenhados demonstram que esses estão sempre empenhados, esforçando-se para desenvolver um trabalho significativo, o que pode ser identificado por meio dos indicadores do IDEB - Índice de Desenvolvimento da Educação Básica no qual a escola vem sempre se destacando.

Sobre esses dados, analisando-se o Projeto Político Pedagógico (PPP) da escola, podese constatar que o indicador para Ensino Fundamental (anos iniciais), aumentou de 3,7, em 
2007, para 4,1, em 2011. Isso não foi diferente no Ensino Fundamental (anos finais). Em 2009, a escola mantinha uma taxa de 3,9, mas em 2013 teve um aumento considerável, atingindo 4,1. Fatores como esses podem ser justificados pela forma de atuação dos docentes e demais profissionais que desenvolvem atividades na instituição.

\section{CONTEÚDOS E METODOLOGIAS NA GEOGRAFIA ESCOLAR}

Considerando os aspectos legais que regem a educação brasileira, como a Lei de Diretrizes e Bases da Educação (LDB - 9.394/1996) e os Parâmetros Curriculares Nacionais, a prática na Geografia Escolar, segundo Kimura (2010), deve estar sempre acompanhada com o planejamento e a sua ação docente, desempenhando assim o exercício significativo entre o fazer e o pensar geográfico voltados para o ensinar-aprender Geografia na educação básica.

Vale salientar que a prática docente deve acontecer juntamente com a teoria. Essas duas vertentes são indissociáveis para o processo de aprendizagem e fazem parte da trajetória fundamental para a aquisição do conhecimento. (KIMURA, 2010).

Em se tratando de planejamento na Geografia Escolar, é importante destacar que esse só terá sentido se for pensado de acordo com os objetivos de ensino. Contudo, ao planejar para curto, médio e longo prazos, faz-se necessário, antes de mais nada, estabelecer suas bases, selecionar conteúdos e metodologias pensando nas concepções de ensino do educando, como também sobre o conhecimento e sociedade que a escola elegeu. (KIMURA, 2010).

Para Libâneo (1994), o ensino compreende-se a partir da mediação dos objetivos, conteúdos e métodos que permitem a junção formativa entre os alunos e os conteúdos escolares, fator indispensável para a aprendizagem do indivíduo.

$\mathrm{Na}$ Geografia, assim como em qualquer outra disciplina escolar, os conteúdos específicos estarão de acordo com o conjunto de saberes resultantes da pesquisa de estudiosos, que fizeram ou fazem parte da produção de conhecimento da ciência durante a história da humanidade. Vale salientar que a seleção de conteúdos escolar, seja na disciplina de Geografia ou em qualquer outra, será definida de acordo com algum tipo de poder. (RABELO; BUENO, 2015).

No Brasil, a seleção de conteúdos escolares, na educação básica pública, muitas vezes segue as sugestões dadas pelo livro didático adotado pela escola. Esses materiais são organizados de acordo com os PCN e chegam à instituição por meio da política pública do livro didático, ou seja, através do Programa Nacional do Livro didático (PNLD). De acordo 
com o Ministério da Educação (MEC), o PNLD possui como finalidade avaliar e proporcionar obras pedagógicas, didáticas e literárias, além de outros materiais de apoio fundamentais para a prática educativa. De forma organizada, o programa regula e garante esses materiais às escolas públicas de educação básica das redes federal, estaduais, municipais e distrital, como também aos ambientes de educação infantil comunitárias, filantrópicas ou confessionais sem fins lucrativos e conveniadas com o Poder Público. ${ }^{2}$

No que diz respeito ao livro didático no Brasil, alguns autores como Rabelo e Bueno (2015) destacam que esse recurso didático não deve ser tido como aparato de verdade única, mas como mecanismo de direcionamento dos conteúdos e de suas aulas. Isso deixa evidente que o posicionamento do autor não deve ser o mais importante, já que cabe a esse profissional definir o que deverá ser ensinado ou não aos seus alunos.

Tendo em vista que os autores dos livros didáticos priorizam conteúdos de interesse nacional, cabe ao docente trazer essa informação para a realidade do educando, partindo, assim, da escala local para a global. Isso implica dizer que o professor não deve estar preso apenas àquilo que se encontra estabelecido nesse material. Tendo em vista que atualmente o uso da tecnologia facilita a aproximação mais rápida com a informação, tanto o educador quanto os alunos têm a possibilidade de usufruir das informações que os cercam. Dessa forma, cabe ao professor trazer novos conceitos e referências e introduzi-las nas aulas, reconhecendo também o conhecimento prévio do aluno a respeito do tema estudado.

Sobre a seleção dos conteúdos e as metodologias na Geografia Escolar, Rabelo e Bueno (2015) destacam que a escola é o ambiente em que o educando tem o acesso ao conhecimento científico, produzido pela humanidade. Seguindo esse pensamento, podemos enfatizar que a Geografia Escolar, através das competências e habilidades a serem desenvolvidas, pode levar o estudante a construir sua cidadania. Dessa maneira, a Geografia enquanto matéria curricular busca proporcionar ferramentas teóricas para o indivíduo compreender o mundo e se identificar enquanto sujeito, entendendo assim a espacialidade dos fenômenos sociais.

De acordo com Rabelo e Bueno (2015), a perspectiva didático-pedagógico corrobora para que os conteúdos na Geografia Escolar sejam discutidos e definidos com finalidades e características específicas, fazendo parte assim do processo educativo. A partir disso, os

\footnotetext{
${ }^{2}$ Informações coletadas sobre os programas do livro didático no Brasil, disponíveis no portal do MEC e portal do Fundo Nacional de Desenvolvimento da Educação (FNDE).
} 
autores aqui citados definem os conteúdos em factuais, procedimentais, atitudinais e conceituais.

Os conteúdos que abordam os fatos e os fenômenos com contribuições de dados servem para as avaliações visando a conferir o conhecimento do educando a partir daquilo que ele decora e/ou memoriza sobre o assunto estudado. Tais aspectos correspondem aos conteúdos factuais. (RABELO; BUENO, 2015).

Nos conteúdos procedimentais, a mediação do professor é necessária. Nessa perspectiva, é importante destacar que, nesse tipo de conteúdo o educando precisa que o professor estabeleça posicionamento sobre o tema estudado e que isso permita a aproximação do assunto ao conhecimento prévio do aluno. (RABELO; BUENO, 2015).

Já os conteúdos atitudinais, por sua vez, intercalam a emoção, os sentimentos, a razão, os valores estéticos e éticos das temáticas estudadas. Nesse contexto, os conteúdos podem se manifestar a partir das relações entre os educandos e a escola. (RABELO; BUENO, 2015).

Rabelo e Bueno (2015) definem os conteúdos conceituais como aqueles que se formam por meio de instrumentos intelectuais para desempenhar o pensamento espacial e realizar o estudo geográfico.

Nessa perspectiva, Garcia (et al, 2014 apud Sales, 2016) destaca que a organização dos conteúdos no Ensino Fundamental e, consequentemente, o seu desenvolvimento devem ser identificados como uma esfera que possibilite aos estudantes desenvolverem competências que lhes proporcionem realizar e desfrutar dos acervos sociais, econômicos e culturais. Além disso, esses conteúdos e a abordagem que a eles deve ser dada assumem papel central, já que é através deles que as decisões da escola são instrumentalizadas, ou seja, demonstradas como ações pedagógicas.

Partindo desse pressuposto de que a organização dos conteúdos é de suma importância para o ensino e aprendizagem da Geografia, podemos destacar que o seu desenvolvimento requer uma atenção especial na definição das metodologias a serem usadas. Assim, pode-se entender que as metodologias para se trabalhar os temas abordados na Geografia não devem ser consideradas como algo superficial aos conteúdos e à prática da análise geográfica. Dessa forma, a metodologia não deve ser tida como receita pronta para se fazer algo em sala de aula. Na verdade, esse mecanismo é apenas uma parcela do conjunto que envolve a temática, a base teórica, o fazer do professor, a conjuntura e os objetivos que se desejam alcançar. (RABELO; BUENO, 2015). 
Seguindo esse pensamento, Carvalho e Pimenta (2011, apud Sales, 2016) destacam que a metodologia consiste ao componente da didática onde o docente estrutura suas atividades de ensino para alcançar objetivos no que diz respeito ao conteúdo específico.

Em suma, a Geografia Escolar orienta-se por meio da produção de significados a partir do cotidiano vivenciado pelo educando, em seu lugar de origem. Dessa maneira, serão esses elementos que possibilitarão ao aluno compreender a sua própria espacialidade e, consequentemente, desenvolver seu raciocínio a respeito dos conteúdos estudados. Portanto, os PCN de Geografia definem que o ensino só será considerável se for relacionado à realidade do estudante. (RABELO; BUENO, 2015).

\section{OS TIPOS DE AVALIAÇÃO E SUAS FINALIDADES}

A avaliação faz parte do cotidiano do ser humano. Durante toda a nossa vida estamos avaliando ou sendo avaliados. Os julgamentos, as análises, os comentários e as comparações realizados durante a nossa rotina diária correspondem às formas pelas quais apreciamos ou criticamos algo. Em outras palavras, avaliamos indiretamente as circunstâncias vivenciadas. (VILLAS BOAS, 2004).

No ambiente escolar, a avaliação também acontece, porém de forma intencional. Nesse sentido, essa ação é proposital e sistemática, podendo trazer consequências positivas ou até negativas para o educando. (VILLAS BOAS, 2004).

Entender os tipos e as diferentes finalidades da avaliação escolar é indispensável já que se trata de um assunto complexo e que merece atenção, pois o ato de avaliar irá, na maioria das vezes, refletir no julgamento, atribuindo valores sobre pessoas, posturas ou atos.

Seguindo esse pensamento, Villas Boas (2008) destaca que a avaliação escolar pode possuir duas finalidades, sendo, em primeiro caso, a de classificar o educando e, em segundo, a de promover sua aprendizagem. Entretanto, a primeira é sempre a mais utilizada. Nessa perspectiva, o professor classifica o aluno por meio de diversas ações, seja através de notas, menções, premiações ou até mesmo através dos rótulos empregados para categorizar os alunos em bons, não tão bons e os ruins.

Dessa maneira, a avaliação escolar voltada para o processo de ensino tem como objetivo avaliar continuamente a aprendizagem, concedendo valores em escalas relativas aos aspectos quantitativos e qualitativos. Para tanto, é necessário que o professor leve em 
consideração os objetivos que se pretende alcançar, definidos através do seu planejamento. (LIBÂNEO, 1994).

Luckesi (2011) destaca que para avaliar é necessário compreender os conceitos teóricos sobre avaliação e acima de tudo, entender como funciona esse processo na prática, pois remeter da teoria para a prática necessita-se de compreensão, conhecimento, análise e, sobretudo a busca de novas formas do saber fazer.

De acordo com Villas Boas (2004), a avaliação na escola acontece de duas formas. Aquela realizada através de exercícios, atividades, provas, produções textuais, entre outras, que consistem na avaliação formal. Nesse procedimento, todos (professores, alunos e pais) estão conscientes de sua execução e nela é sempre atribuída uma pontuação, menção ou conceito. Além disso, existe a avaliação informal, que é muito usada na educação infantil e nos anos iniciais do ensino fundamental. Nesse caso, o professor analisa a interação do educando dentro e fora da sala de aula. Por meio disso, o docente tem a oportunidade de observar a postura do aluno, bem como sua participação individual e coletiva nas aulas e na produção das atividades como um todo.

Nessa perspectiva, Villas Boas (2004) também destaca que a maior divergência existente entre essas duas formas de avaliar está atrelada ao fato de que, diferente da avaliação formal, a informal não é sempre prevista e, dessa maneira, o público avaliado não sabe que está em processo de análise, então, essa ação requer muita ética durante sua execução.

A partir disso, compreende-se que é necessário conceituar os tipos de avaliação, bem como suas finalidades, para assim entender o seu conceito e as formas corretas de avaliar as práticas pedagógicas.

Dessa forma, Turra et al. (1986) descreve a avaliação em três modalidades: a diagnóstica, a formativa e a somativa. Nessa perspectiva, o conceito de modalidade para avaliação, segundo o autor, compreende a uma terminologia usada para caracterizar os tipos de avaliação e seu ordenamento. Sendo assim, as designações corresponderão à função assumida por essa ação.

Para Turra et al. (1986) a avaliação diagnóstica corresponde a uma analise inicial do aluno e normalmente acontece no nos primeiros dias do ano letivo. Essa ação permite que o professor faça levantamentos a respeito do conhecimento prévio do educando, considerando como pré-requisito para discussões posteriores do conteúdo que será abordado. Vale salientar 
que os dados obtidos por meio disso não devem ser utilizados na progressão do indivíduo, mas, servir apenas como indicativo para o docente.

Segundo Freitas et al. (2014) a avaliação diagnóstica tem o intuito de verificar a presença ou não de conhecimentos e habilidades pré-determinados pelos educandos. De fato, trata-se de uma dinâmica inicial do processo avaliativo que possibilita ao professor conhecer de forma individual, aquilo que os alunos já dominam e que serão essenciais para as aprendizagens posteriores.

Já a avaliação formativa, de acordo com Villas Boas (2004), consiste no ato de avaliar visando à promoção da aprendizagem do aluno e do professor e consequentemente da escola. Nessa abordagem, o objetivo principal é a valorização do processo de aprender do estudante, visando a sua inclusão no ambiente escolar.

Nessa perspectiva, Rabelo e Bueno (2015) complementam que esse tipo de avaliação compreende-se como um mecanismo pedagógico do processo de ensino-aprendizagem. Dessa maneira, sua funcionalidade vai muito além da prática classificatória ou seletiva do educando, já que ela visa acima de tudo proporcionar ao aluno possibilidades de desenvolvimento na construção do seu conhecimento.

Contrapondo esse pensamento, Turra et al. (1986) compreendem como avaliação somativa, aquela que tem como objetivo classificar os resultados do processo de aprendizagem do aluno. Assim, essa prática permite que os dados obtidos por meio do desempenho do educando sejam quantificados.

Considerando essa discussão, Sadler (1989 apud Villas Boas, 2004) compreende avaliação somativa como aquela que é usada para fazer levantamentos e medir tudo aquilo que foi apreendido pelo aluno no fim de um dado período (bimestre, ano letivo, entre outros). Nesse contexto, o objetivo central é mensurar o índice de desempenho do aluno e, a partir disso, retribuí-lo com uma nota ou certificação.

Contudo, após essa discussão, fica evidente que cada tipo de avaliação possui finalidades específicas que podem ser usadas nos mais diversos anglos do processo avaliativo. Entretanto, suas funções irão variar de acordo como o planejamento e os objetivos que se pretendem alcançar. Dessa forma, o professor deve estar sempre atento na hora de selecionar o método avaliativo a ser usado, já que sua ação recairá diretamente sobre o educando, deixando consequências positivas ou negativas no seu processo de ensino e aprendizagem.

\section{OS INSTRUMENTOS AVALIATIVOS}


Avaliar corresponde à representação da realidade vivenciada na escola e em especial, na sala de aula; do índice de aprendizagem do aluno e da reflexão da prática e metodologias adotadas pelo docente. Desse modo, isso só é possível através do uso de instrumentos avaliativos que permitam a coleta e a análise de dados, possibilitando detalhes sobre a realidade da turma no que diz respeito ao índice de aprendizagem de cada aluno (LUCKESI, 2011).

Para Luckesi (2011), a coleta de dados corresponde às condições impostas pelos objetivos, atrelados ao processo de ensino-aprendizagem. Para isso, é necessário que estes estejam em consonância como o Projeto Político da escola, bem com os planos de ensino e, consequentemente, com o planejamento das aulas. De tal modo, o professor necessita estabelecer previamente os instrumentos que possibilitem avaliar o conteúdo estudado, sendo este coeso com aquilo que foi tratado durante as aulas.

Assim, vale salientar que os instrumentos precisam ser elaborados, aplicados e corrigidos de acordo com os critérios estabelecidos durante o planejamento das aulas. Para tanto, esses mecanismos devem ser construídos seguindo regras científicas metodológicas, devendo estar adequados à realidade do educando, funcionando assim como elemento satisfatório para a coleta de dados e para a prática da avaliação da aprendizagem. (LUCKESI, 2011).

Em outras palavras, ao se planejar a avaliação, o professor deve está atento à organização, levando em consideração os instrumentos a serem usados, conferindo uma avaliação sistemática e, ao mesmo tempo, estabelecer se sua descrição será de cunho quantitativo ou qualitativo. Levando em consideração a criatividade desse profissional, cada atividade elaborada poderá desencadear um novo instrumento avaliativo, que poderá ser usado e adequado a situações específicas. (STEFANELLO, 2009).

Dessa maneira, Turra et al. (1986) considera que os instrumentos ou técnicas de avaliação, como por exemplo: a técnica de testagem (testes e provas); as fichas de controle e a observação; questionário e entrevista; as técnicas de sociograma e sociometria, que servem como mecanismos para o professor enquanto avaliador, correspondem a uma gama de fatores que se bem ajustados aos objetivos propostos, podem trazer resultados significativos para a aprendizagem do educando.

Portanto, para serem utilizados na rotina escolar, esses instrumentos avaliativos devem ser bem planejados e elaborados, de forma a se adequar aos objetivos e finalidades da 
avaliação. De tal modo, esses instrumentos podem variar de acordo com o planejamento e o propósito de execução, mas devem abranger questões específicas, sem apresentar ambivalências; deve conter um único conteúdo em cada questão; ser escrito com uma linguagem clara e acima de tudo, respeitar os esforços de estudar e aprender de cada aluno (LUCKESI, 2011).

\section{AS PRÁTICAS AVALIATIVAS DOS PROFESSORES}

A educação é uma prática social que acontece em diversos ambientes, seja na família, na escola, no grupo sindical, na igreja, no trabalho, entre outros. Essa interação nos revela que a todo momento o indivíduo está construindo conhecimento que pode ser manifestado sobre influência de uma pedagogia familiar, escolar e até mesmo política. Porém, a atividade realizada pelo professor é tida como a prática educativa mais vasta que ocorre na sociedade. Diante desse pensamento, podemos considerar que o professor e suas práticas pedagógicas são grandes influenciadores da aprendizagem do homem como ser social. (LIBÂNEO, 1994).

De acordo com Libâneo (1994), a prática educacional não é somente uma imposição da vida em sociedade. Ela também colabora para a promoção do conhecimento individual e coletivo das pessoas em relação às experiências culturais e sociais. Isso implica dizer que, a partir dessa interação, o homem tem a capacidade de atuar no meio, modificando-o de acordo com suas necessidades. Essas manifestações irão acontecer por meio das vivências, valores, experiências, costumes e técnicas adquiridas ao longo da história e que passarão para as futuras gerações.

Nesse contexto, a prática educativa faz parte de uma variável considerável de instituições e movimento social, resultantes dos aspectos políticos, econômicos, religiosos e culturais que direta ou indiretamente influem na vida humana. Essas diversas modalidades de educação podem ocorrer por meio da educação intencional e não-intecional. (LIBÂNEO, 1994).

A educação intencional, também considerada como educação formal, corresponde à ação e finalidade dadas pelas instituições escolares, igrejas, entre outras, onde o educador tem por obrigação cumprir com ações de ensino e objetivos sistematizados em uma atuação pedagógica baseada em procedimentos didáticos. Nessa perspectiva, a escola recebe ênfase entre as outras formas, já que essa se destaca como um campo de base e pressuposto para as demais. (LIBÂNEO, 1994). 
Entende-se como educação não-intecional ou educação informal aquela em que acontece a influencia do meio social e ambiental em relação ao indivíduo. Nesse cenário, as experiências de vida, o convívio coletivo, valores e ideais que não são oferecidas por uma instituição, seja ela educacional ou não, permitem que o homem adquira conhecimento a partir da sua interação com os aspectos aqui citados. (LIBÂNEO, 1994).

De acordo com Franco (2015), as práticas pedagógicas são determinadas pelas práxis, ou seja, a junção reflexiva da teoria com a própria prática docente. $\mathrm{O}$ autor ainda destaca que os saberes pedagógicos seguem percursos entre as parcialidades, culturas, práticas e sujeitos, presentes dentro e fora da escola. Nesse contexto, a pedagogia leva a reflexões e a didática, focada nos aspectos escolares da sala de aula, colabora para a instauração dos saberes escolares. Contudo, a didática irá se fundamentar na construção da aprendizagem do educando por meio do ensino antecipadamente planejado. Dessa forma, a didática se constitui como prática pedagógica.

Sobretudo, Franco (2015) ainda destaca que os métodos de materialização das experiências de ensinar e aprender acontecem através das práticas pedagógicas. Isso implica dizer que a aprendizagem do indivíduo se dá por meio dos diversos ensinamentos presentes nas vivências pessoais e que acabam potencializando as competências do ensino escolar. Dessa maneira, o desafio pedagógico hoje é transformar o ensino escolar tão interessante e eficaz quanto outros que permeiam a realidade dos alunos.

Franco (2015) considera também que as interações existentes entre aluno, professor, escola e currículo permitem um convívio dimensional e paradoxal, entre o indivíduo que aprende e o sujeito que prepara e organiza as condições para ensinar, no caso, o professor. Com isso, o docente deve buscar meios para viver a discrepância das questões e conformidades dadas pelo aluno, agindo como estimulador da aprendizagem.

Nas três turmas dos Anos Iniciais do Ensino Fundamental existentes na escola, constatou-se que, ao apresentar os conteúdos de Geografia aos alunos, as docentes costumam fazer uma sondagem, como forma de identificar aquilo que os educandos carregam consigo sobre o contexto abordado. Em linhas gerais, as professoras iniciam a apresentação do assunto, fazendo indagações que possibilitem ao aluno interagir com o que está sendo abordado.

As práticas adotadas pelos professores em discussão promovem o encontro do aluno com o conteúdo estudado. Seguindo essa informação, para Libâneo (1994), o docente deve 
propor condições de mediar o educando em relação à vida social, considerando suas condições de origem. Sendo assim, os meios usados para essa aproximação, como a organização do ensino, os saberes e métodos pedagógicos são fundamentais para propiciar a aprendizagem do indivíduo.

São atitudes como essa que, segundo Franco (2015), despertam interesse nos alunos. Dessa maneira, as situações que os desafiam são as mesmas que colaboram para o retorno em forma de produções, por meio de suas experiências e interações que envolvem as vivências atuais e as interpretações instigadas pelos desafios dados pelo professor. Assim, toda essa ação favorece a similitude do processo de ensino e aprendizagem, identificado em sua diversidade e dimensão.

Em uma das turmas observadas, a professora desenvolveu a aula sobre os mapas e teve como base teórica o livro didático. Para iniciar a discussão, a docente realizou indagações, dentre as quais podemos destacar: "para representar o espaço da nossa escola por meio de um mapa, faz mais sentido fazer em tamanho reduzido ou em tamanho real?’. Por meio disso, a participação da turma foi imediata e a experiência foi o necessário para a mesma destacar que o tamanho de um mapa terá variações de acordo com a escala. Além desse aspecto, também foram expostos os tipos de mapas, dando ênfase para os mapas políticos e físicos e os demais elementos que compõe um mapa (título, ícone de direção e legenda).

Como forma de avaliar o que a turma compreendeu sobre o assunto, a professora sugeriu a realização de uma atividade presente no livro que ao ser realizada, foi corrigida no quadro. Para aprimorar a discussão, os alunos foram orientados a pesquisar (em casa) imagens que tratassem sobre problemas ambientais representados nos mapas do exercício e trouxessem na aula seguinte. Esse material seria usado para a construção de um mural temático.

Sobre o uso do livro didático, Stefanello (2009) destaca que o professor deve, antes de mais nada, explorar a fundo esse recurso. Porém, mesmo que o livro seja rico, considerando a realidade aqui descrita, o autor enfatiza que apenas as representações cartográficas presentes nesse material didático não são suficientes. Dessa forma, para melhorar a discussão, o mesmo sugere que o educador tenha como auxílio os mapas e/ou globos disponíveis na escola.

Mesmo sendo crianças, os conteúdos cartográficos já devem ser usados no ensino de Geografia. Em se tratando disso, Simielli (2007, apud Stefanello, 2009) considera que mesmo nos anos iniciais do ensino fundamental o educando deverá ter a possibilidade de conhecer os 
elementos de representação gráfica, para que, nos anos seguintes da educação básica, tenham a oportunidade de trabalhar com a representação cartográfica.

A aproximação do assunto com a realidade da turma permitirá que os estudantes interajam com maior rapidez em relação ao que está sendo debatido. Nesse contexto, Simielli (2007, apud Stefanello, 2009) destaca que o modo usado pelo docente de trazer o assunto estudado para a realidade do educando é o mais indicado, visto que nos anos iniciais do ensino fundamental esse conteúdo deve partir daquilo que está mais próximo da vida do aluno (rua, bairro, escola), para que, nos anos seguintes, sejam trabalhados espaços mais amplos (município, estado, país, planisfério).

Em outra realidade, a professora selecionou como conteúdo a importância da água. Para prosseguir com a discussão, é indispensável enfatizar que nessa turma, devido ao censo anterior, o número de livros didáticos não foi suficiente para os alunos, dessa forma, como nem as famílias nem a escola têm condições de fazer cópia desse material, a professora transcreve textos seguindo o roteiro sugerido pelo livro didático. Para ilustrar o conteúdo, ao fim da discussão, a docente sugere que os próprios alunos desenhem aquilo que compreenderam.

O texto escrito apresentava características como: a importância da água para a vida no planeta; sua disponibilidade, relacionando a existência em porcentagem e comparando sua quantidade (doce, salgada e em geleiras); suas formas de uso; proteção e cuidado como garantia para as futuras gerações.

O conteúdo foi explorado após a escrita do texto. A professora iniciou a discussão interrogando a turma sobre o que eles compreendiam do assunto e para facilitar a explanação do conteúdo, a docente selecionou palavras e termos (poluição da água; importância e disponibilidade da água doce no planeta) existentes no contexto descrito.

Para esclarecer a porcentagem de água doce (em reservatórios e nas geleiras), salgada e polida (descritas no quadro), a docente fez um gráfico em forma de pizza e, em seguida, discutiu o custo benefício de se utilizar a água em forma de gelo e o processo de dessalinização da água do mar, contextualizando todos esses aspectos com a realidade dos educandos.

A participação da turma foi significativa. Cerca de $70 \%$ dos integrantes demonstrou conhecimento e preocupação com o cuidado desse recurso natural, demonstrando que o seu uso correto, em determinadas situações da rotina diária, pode refletir na garantia da água para 
as gerações futuras. Isso implica dizer que o conhecimento geográfico enquanto disciplina escolar permite que o aluno possa construir significados para sua formação enquanto ser social.

Dessa forma, Buitoni (2010) considera que a prática de ensino que leva o educando a entender os acontecimentos do cotidiano, considerando a sua realidade e o que foi vivenciado no seu lugar de origem, facilita a compreensão de que o mundo é construído a partir das relações sociais e que cada um desempenha sua parte nesse processo.

Sendo assim, o uso de ferramentas apropriadas é fundamental para que o estudante exercite sua percepção e reflita sobre os acontecimentos do cotidiano. Com o auxílio da seleção correta de metodologias e conteúdos realizada pelo docente, esse indivíduo será capaz de superar a proporção individual, fundamental para identificação do conhecimento social e da formação do cidadão.

Na observação do último cenário, a turma estava respondendo a um exercício proposto pela professora, relacionado ao conteúdo trabalhado na aula anterior. Na oportunidade, foi possível identificar a preocupação dessa profissional com a leitura e a escrita dos educandos em relação ao contexto estudado.

Sobre isso, Pontuschka (2009) considera que é papel do professor, seja qual for a disciplina, estimular o educando a enxergar os estudos como uma atividade interessante e significativa. Nesse contexto, se o aluno demonstrar dificuldades na leitura e na escrita, como também no processo de análise e reflexão sobre um texto, o docente deverá orientá-lo, mesmo sendo na aula de Geografia. Sendo assim, o educador pode oferecer mecanismos que facilitem a compreensão do indivíduo, para que esse desenvolva sua capacidade de entender a realidade social com maior ênfase.

Portanto, baseado no pensamento de Filizola (2009), a prática de ensino na Geografia Escolar, ou seja, as metodologias, os conteúdos e a avaliação não devem ser pensados com o objetivo de reproduzir os programas das universidades, mas planejados para um ensinar que desperte no educando o interesse em aprender. Isso contribuirá para a formação da sua consciência espacial e com o desempenho do conhecimento geográfico, contribuindo assim, para a inclusão social e o desempenho da cidadania ativa.

\section{ALGUMAS CONCLUSÕES}


Esta produção científica manteve-se focada na Geografia Escolar e na avaliação da aprendizagem. Ao longo de sua elaboração, foi possível evidenciar análises e ao mesmo tempo refletir sobre a avaliação da aprendizagem desenvolvida nas aulas de Geografia por docentes dos Anos Iniciais do Ensino Fundamental da Escola Estadual Senador José Bernardo.

Caracterizar o ambiente escolhido para o desenvolvimento da pesquisa foi fundamental para que o leitor pudesse conhecer o espaço escolar e suas especificidades, principalmente no que diz respeito aos aspectos históricos de fundação e o perfil docente da instituição.

A discussão sobre os conteúdos e as metodologias utilizadas na Geografia Escolar deram o suporte inicial para uma discussão posterior sobre os tipos de avaliação e suas finalidades, além dos instrumentos avaliativos, para assim, contextualizar uma reflexão sobre as práticas dos professores nas aulas desse componente curricular.

Contemplar esses aspectos permitiu conhecer as diversidades de concepções sobre essa ciência e seu ensino na educação básica, visto que a Geografia enquanto disciplina escolar permite contribuir para a formação intelectual dos professores e educandos através do enriquecimento das representações sociais.

Por meio dos conhecimentos construídos mediantes as aulas de Geografia durante sua vida escolar, o sujeito enriquece seu pensamento sobre os aspectos sociais e as transformações espaciais ocorridas ao longo do tempo, tendo assim, a capacidade de interagir em várias situações e assumir posições diante dos acontecimentos diários.

Conhecer o tipo de avaliação ou instrumentos avaliativos desenvolvidos na Geografia Escolar faz parte de uma ação que requer atenção, pois esses aspectos estão diretamente ligados ao processo de ensino e aprendizagem do educando. Dessa maneira, nas aulas de Geografia ou em qualquer disciplina escolar, o professor não deve estar obsoleto das tecnologias, nem tão pouco desconsiderar conhecimento prévio do educando.

Portanto, aproveitar as informações prévias que o educando carrega consigo sobre os conteúdos estudados e conhecer a avaliação e suas finalidades, realizando-as por meio dos instrumentos corretos, são fatores essenciais para constatar o desempenho do estudante na construção do conhecimento e os elementos que colaboram para esse progresso. Dessa forma, o que mais importa durante o processo avaliativo do aluno é que o professor seja capaz de identificar as dificuldades existentes e, através disso, buscar soluções para suprir as 
necessidades, com o intuito de permitir que o sujeito aprenda e desenvolva seus aspectos cognitivos.

\section{REFERÊNCIAS}

ALMEIDA, D. L. de. Educação Moral e Cívica na ditadura militar: um estudo de manuais didáticos. 2009. 193 f. Dissertação (Mestrado em Ciências Humanas) - Universidade Federal de São Carlos, São Carlos, 2009.

BRASIL. Lei 9.394/96, de 20 de dezembro de 1996. Disponível em: <http://portal.mec.gov.br/seesp/arquivos/pdf/lei9394_ldbn1.pdf>. Acesso em 14 de jul. 2018.

Ministério da Educação. Fundo Nacional de Desenvolvimento da Educação (FNDE). Disponível em: <http://www.fnde.gov.br/programas/livro-didatico/livro-didatico-dados-estatisticos>. Acesso em: 16 jul. 2018.

Ministério da Educação. Programa Nacional do Livro Didático (PNLD). Disponível em: <http://portal.mec.gov.br/pnld/apresentacao>. Acesso em: 18 jul. 2018.

BUITONI, M. M. S. Geografia: ensino fundamental. Brasília: Ministério da Educação Básica, 2010. 252p. (Coleção Explorando o Ensino; v. 22).

FILIZOLA, R.. Didática da Geografia: proposições metodológicas e conteúdos entrelaçados com a avaliação. Curitiba: Base Editorial, 2009. 120p.

FRANCO, M. A. S. Práticas pedagógicas de ensinar-aprender: por entre resistências e resignações. Educ. Pesqui., São Paulo, v. 41, n. 3, p. 601-614, jul./set. 2015.

FREITAS, S. L; COSTA, M. G. N. da; MIRANDA, F. A. de. Avaliação Educacional: formas de uso na prática pedagógica. Meta: Avaliação | Rio de Janeiro, v. 6, n. 16, p.85-98, jan./abr.2014.

KIMURA, S. Geografia no ensino básico: questões e propostas. 2. ed. São Paulo: Contexto, 2010.

LIBÂNEO, J. C. Didática. São Paulo: Cortez, 1994. - (Coleção magistério. $2^{\circ}$ grau. Série formação do professor).

LUCKESI, C. C. Avaliação da aprendizagem escolar: estudos e proposições. 22. ed. São Paulo: Cortez, 2011.

PONTUSCHKA, N. N. Para ensinar e aprender Geografia. 3. ed. São Paulo: Cortez, 2009. (Coleção docente em formação. Série Ensino Fundamental).

RABELO, K. S. de P.; BUENO, M. A. Currículo, políticas públicas e ensino de geografia. Goiânia: ed. da PUC Goiás, 2015. 252 p.

RIO GRANDE DO NORTE. Secretaria de Estado da Educação e da Cultura. Escola Estadual Senador José Bernardo. Projeto político pedagógico. São João do Sabugi, 2016. 28p.

SALES, L. P. de A. Processo de ensino de geografia nos anos iniciais do ensino fundamental: uma análise em uma escola pública do município de Ouro Branco-RN. Caicó, RN: UFRN, 2016. 
STEFANELLO, A. C. Didática e avaliação da aprendizagem no ensino de geografia. São Paulo: Saraiva, 2009. 159p.

TURRA, C. M. G. et al. Planejamento de ensino e avaliação. 11. ed. Porto Alegre: Sagra Luzzatto, 1986.

VILLAS BOAS, B. M. de Freitas. Portfólio, avaliação e trabalho pedagógico. Campinas, SP: Papirus, 2004. - (Coleção Magistério: Formação e trabalho Pedagógico).

Virando a escola do avesso por meio da avaliação. Campinas, SP: Papirus, 2008. (Coleção Magistério: Formação e trabalho Pedagógico). 